\title{
Ballistic Trauma in 1991/92 War in Osijek, Croatia: Shell Fragments Versus Bullets
}

\author{
Z Lovrić \\ $\mathrm{MD}$ * \\ Surgeon \\ H Kuvězdic \\ MD \\ Urologist \\ D Prlić \\ MD
}

B Wertheimer

MD

Orthopaedic Surgeon

$\mathrm{K}$ C̆andrlić

MD

Surgeon

Department of Surgery, Osijek Clinical Hospital, J. Huttlera 4, 54000 Osijek, Croatia

SUMMARY: During 18 months of the 1991/92 war against Croatia, 4,545 injured were treated at the Departmenf of Surgery of Osijek Clinical Hospital. Some, 2,544 (55.9\%) sustained shell fragment injuries and $807(17.8 \%$ bullet injuries. Shell fragments lead to a higher number of polytraumatized patients than did bullets $(6.8 \%$ versug $5.3 \%)$. The postoperative complication rate for fragment injury $(5.8 \%)$ was significantly higher than that for bulle injury $(4.1 \%)$. Mortality rate did not differ significantly (3.9\% versus $4.5 \%$ respectively).

\section{Introduction}

Since August 26, 1346, when the first cannon was used in the Battle of Crecy, mankind has rushed to invent more sophisticated devices of destruction. Observations on wounds are almost as old as the history of manmade fireweapons. Numerous reports have dealt with bullet injuries including experimental studies on tissue damage (1-6). However there are few reports on shell fragments as a causative agent (7-9).

The 1991 conflict involving Croatia prompted a transformation of Osijek General Hospital to a War Hospital for the north eastern part of the country (10-13). In this report, we review our experiences with shell fragment and bullet injuries treated at the Department of Surgery during the period 2 May 1991 to I November 1992. We wanted to test our empirical observation that, regardless of higher importance given to high-velocity bullets in current reviews, the injuries caused by shell fragments were equally serious. This report forms part of a study of 4,545 injured and 780 deceased brought directly to the Pathology department from the streets or battlefields (1215). In prehospital mortality, shell fragments were the cause of death in $62 \%$ of cases.

* now Division of Traumatology, Department of Surgery, Clinical Hospital Dubrava, 10000 Zagreb, Av Izvidaca 6, Croatia.
Patients and Methods

During the 18 months period, 4,545 injured were admitted to the Department of Surgery of Osijek Clinical Hospital. There were 2,544 (56\%) shell fragment injuries, and $807(18 \%)$ bullet wounds resulting from rifle, automatic weapon or pistol fire. Blunt injuries and other causes of trauma were found in $1,194(26.2 \%)$ patients.

The most experienced surgeon was the head of triage which was performed at the entrance hall in the basement of the Department of Surgery. Almost $70 \%$ were wounded in the city streets and surrounding villages. Most had had no opportunity for first aid administration at the site of injury because of the continuous heavy attacks on the city $(10,14)$. Therefore, the Department of Surgery represented all four recognised echelons of management of war casualties $(10,13,16,17)$. They divided casualties into two main groups: those requiring rapid resuscitation and diagnostic procedures, were processed through an "urgent line". Non vital injuries were managed through a "cold line". The indication for urgent surgery was prioritized on $\widetilde{N}$ the basis of overt, major, life threatening bleeding, N response to urgent resuscitation and the demands of individual injuries in polytraumatized patients. 
The terms mono-, multi- and polytrauma have been used at the Department of Surgery, Osijek Clinical Hospital for more than 25 years. Monotrauma means injury of only one organic system. Multi- and polytrauma include injuries of two or more organic systems or anatomical regions, but in the case of polytrauma at least one is life threatening.

Of the 4,545 injured, 3,942 were men and 603 women, of these 1,828 were civilian, and 2,717 were members of the Croatian National Guard or Croatian Police.

Chi-square test was used for all statistical analyses and a value of $\mathrm{p}<0.05$ regarded as significant.

\section{Results}

Among those patients wounded by shell fragments $(2,544), 2,144(84.3 \%)$ were men and $400(15.7 \%)$ women. The mean age was 34 years (range 1 to 87 ). There were 1,213 (26.7\%) civilians and 1,331 (29.3\%) members of the Croatian National Guard or Croatian Police. Mean evacuation time was 1 hour (range $5 \mathrm{~min}$ to 14 hours).

In the group of patients wounded by bullets (807) 247 (30.6\%) were civilians and $560(69.4 \%)$ members of the Croatian National Guard or Croatian Police. There were $768(95.2 \%)$ men and $39(4.8 \%)$ women. The mean age was 31.5 years (Table 1 ).

Of the 2,544 patients wounded by shell fragments $12.2 \%$ were in shock on admission, compared with $11.8 \%$ of 807 wounded by bullets. Diminished consciousness was present in $5.3 \%$ of the wounded by shell fragments and in $6.4 \%$ of the wounded by bullets.

Of all injured, 3,564 (78.4\%) patients sustained monotrauma, $753(16.6 \%)$ multitrauma and $228(5.0 \%)$ polytrauma. When wounded by shell fragment, 1,793
(70.4\%) were monotraumatized, $579(22.8 \%)$ multitraumatized and $172(6.8 \%)$ polytraumatized. In the group of wounded by bullets, $689(85.3 \%)$ were monotraumatized, $75(9.3 \%)$ multitraumatized and 43 (5.3\%) polytraumatized. The difference between those wounded by shell fragments and those by bullets was highly significant, except for the frequency of polytrauma (Table 2).

The list of primary operations done in both groups of patients is shown in Table 3. Significantly higher proportions of shell fragment wounded patients underwent amputations ( $p>0.05$ ), laminectomy ( $p>$ $0.001)$ and plastic and reconstructive surgery $(\mathrm{p}<0.05)$, whereas a significantly higher proportion of bulletwounded patients underwent craniotomy $(\mathrm{p}<0.01)$ and wound excision $(\mathrm{p}<0.05)$.

We performed secondary closure or coverage between 14 and 21 days. A higher proportion of wounds caused by shell fragments required skin coverage by means of plastic and reconstructive procedures compared to bullet wounds $(\mathrm{p}<0.05)$ (Table 3$)$.

Ninety-nine patients with shell injuries out of a total of $2,544(3.9 \%)$ died as a direct result of their injuries. This compared with 36 of $807(4.5 \%)$ with bullet wounds. The difference fails to reach statistical significance.

Complications as listed in Table 4 occurred in 148 $(5.8 \%)$ cases wounded by shell fragment and $33(4.1 \%)$ cases of those wounded by bullet $(\mathbf{p}<0.05)$. Similar rates of infection, bleeding, wound disruption thromboembolism, cardiac, respiratory and urinary $\vec{\theta}$ problems were observed in the two groups. The frequency of secondary bleeding however was significantly higher in patients wounded by shek fragments $(\mathrm{p}<0.05)$.

Table 1

General data on 4,545 patients wounded in 1991/92 war in Osijek, Croatia

\begin{tabular}{lccc}
\hline All & $\begin{array}{c}\text { No. of Patients Injured } \\
\text { by Shell Fragment }\end{array}$ & Bullet & Other \\
\hline Men & $2,144(84.3 \%)$ & $768(95.2 \%)$ & $1,030(86.3 \%)$ \\
Women & $400(15.7 \%)$ & $39(4.8 \%)$ & $164(13.7 \%)$ \\
Civilians & $1,213(47.7 \%)$ & $247(30.6 \%)$ & $368(30.8 \%)$ \\
CRO Army Police & $1,331(52.3 \%)$ & $560(69.4 \%)$ & $826(69.2 \%)$ \\
\hline Totals & $2,544(55.9 \%)$ & $807(17.8 \%)$ & $1,194(26.2 \%)$ \\
\hline
\end{tabular}

Table 2

Type and cause of trauma in 4,545 patients wounded in 1991/92 war in Osijek, Croatia

\begin{tabular}{lcccc}
\hline Type & Shell Fragment & $\mathbf{p}<$ & Bullet & All \\
\hline Monotrauma & $1,793 / 2,544$ & 0.001 & $689 / 807$ & $3,564 / 4,545$ \\
& $(70.5 \%)$ & & $(85.4 \%)$ & $(78.4 \%)$ \\
Multitrauma & $579 / 2,544$ & 0.001 & $75 / 807$ & $753 / 4,545$ \\
& $(22.8 \%)$ & & $(9.3 \%)$ & $(16.6 \%)$ \\
Polytrauma & $172 / 2,544$ & 0.2 & $43 / 807$ & $228 / 4,545$ \\
& $(6.8 \%)$ & & $(5.3 \%)$ & $(5.0 \%)$ \\
\hline Total & $2,544(100 \%)$ & & $807(100 \%)$ & $4,545(100 \%)$ \\
\hline
\end{tabular}


Table 3

Comparison of primary operations done in patients wounded by shell fragment or bullet

\begin{tabular}{lrcr}
\hline Operation & \multicolumn{2}{c}{ No. of Operations in Patients Wounded by } & Bullet \\
& Shell Fragment & $\mathbf{8 0 7}$ \\
\hline Amputation & $\mathbf{2 , 5 4 4}$ & 0.05 & $12(1.5 \%)$ \\
Arthrotomy & $74(2.9 \%)$ & $\mathrm{NS}$ & $(0.6 \%)$ \\
Craniotomy & $16(0.6 \%)$ & 0.01 & $36(4.5 \%)$ \\
Wound Excision & $67(2.6 \%)$ & 0.05 & $647(80.0 \%)$ \\
Lumbotomy & $1,953(76.8 \%)$ & $\mathrm{NS}$ & $3(0.4 \%)$ \\
Laminectomy & $5(0.2 \%)$ & 0.001 & $6(0.8 \%)$ \\
Laparotomy & $79(3.1 \%)$ & $\mathrm{NS}$ & $53(6.6 \%)$ \\
Osteosynthesis & $145(5.7 \%)$ & $\mathrm{NS}$ & $24(3.0 \%)$ \\
External Fixation & $54(2.1 \%)$ & 0.05 & $38(4.7 \%)$ \\
Plastic-Reconstruction & $127(5.0 \%)$ & $\mathrm{NS} 8$ & $13(1.6 \%)$ \\
Thoracophrenolaparotomy & $79(3.1 \%)$ & $\mathrm{NS}$ & $8(1.0 \%)$ \\
Tracheotomy & $14(0.6 \%)$ & $\mathrm{NS}$ & $4(0.5 \%)$ \\
Thoracotomy & $5(0.2 \%)$ & $\mathrm{NS}$ & $27(3.3 \%)$ \\
Vascular Reconstruction & $90(3.5 \%)$ & & $32(4.0 \%)$ \\
\hline
\end{tabular}

NS = non-significant

Table 4

Complications in patients wounded by shell fragment or bullet

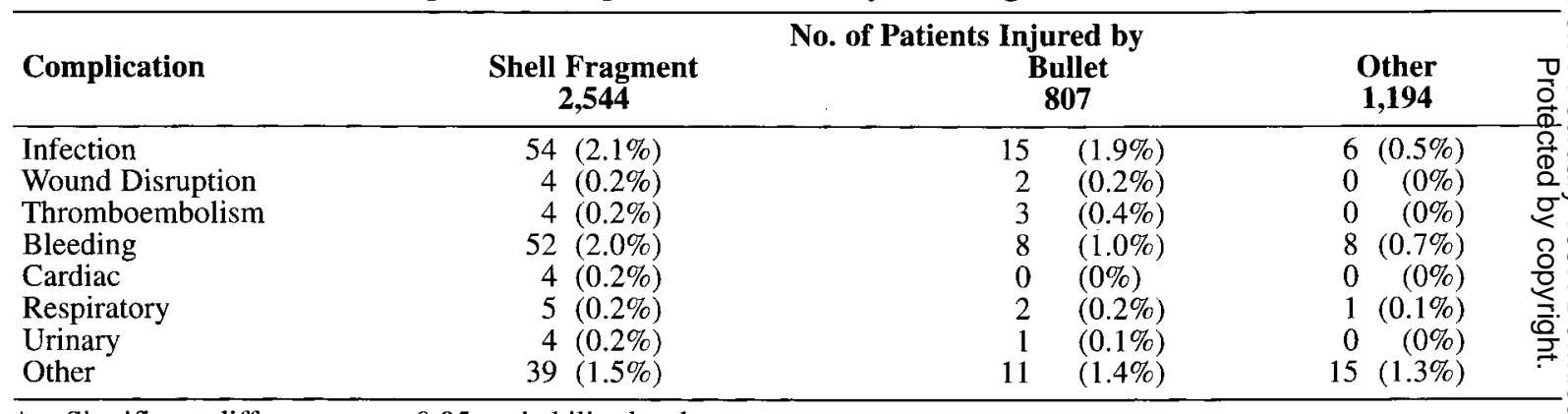

$*$ = Significant difference at $\mathrm{p}<0.05$ probability level

Table 5

Region and cause of wounding of 4,545 patients in 1991/92 war in Osijek, Croatia

\begin{tabular}{lrrrrr}
\hline Region & Shell Fragment & \multicolumn{2}{c}{ No. of Patients Injured by } \\
Bullet & Other & All \\
\hline Head-neck & $630(17.0 \%)$ & $*$ & $90(9.9 \%)$ & $95(43.5 \%)$ & $815(16.9 \%)$ \\
Thoracic & $589(15.9 \%)$ & $119(13.1 \%)$ & $8(3.7 \%)$ & $716(14.8 \%)$ \\
Abdominal & $428(11.5 \%)$ & $105(11.5 \%)$ & $5(2.3 \%)$ & $538(11.1 \%)$ \\
Upper extr. & $924(24.9 \%)$ & $238(22.1 \%)$ & $81(37.2 \%)$ & $1,243(25.7 \%)$ \\
Lower extr. & $1,137(30.7 \%)$ & $*$ & $360(39.5 \%)$ & $29(13.3 \%)$ & $1,526(31.5 \%)$ \\
\hline Total & $3,708(100 \%)$ & $912(100 \%)$ & $218(100 \%)$ & $4,838(100 \%)$ \\
\hline
\end{tabular}

* Significantly different $(\mathrm{p}<0.001)$

A review of the region of injury with respect to the mode of wounding is shown in Table 5. Significantly higher numbers of head and neck injuries were caused by explosive devices $(17.0 \%)$ than by bullets $(9.9 \%)$, whereas the proportion of bullet wounds was significantly more frequent in the lower extremities $(30.7 \%$ versus $39.5 \%$ respectively; $\mathrm{p}<0.001$ ).

\section{Discussion}

Much has been written about extensive tissue damage $\rightarrow$ and importance of high-velocity missiles (1-3), but few reports have reviewed injuries by shrapnel $(7,9,15,16,17)$. $\sim$ Our data concerning wounding by shell fragments, $55.9 \%$ of those injured, is similar to that of other campaigns of this century; World War I $=61 \%$, World War $11=85 \%$, 
Vietnam $=44 \%$, Israel, $1982=53 \%$, Falklands $=55.8$ (16). Mortars and similar devices are designed to main rather than to kill. When targeted at civilians, the) produce mass wounding chaos and evacuation problems $(10,12)$. Most of those wounded by shell fragments in the study occurred in the streets of the city of Osijek nearby villages (15). Shell fragment wounds usually happen at a close range (100 metres). Higher mass and impact velocity similar to that of a bullet (18), means that an individual shell fragment can produce similar destructive effects to a bullet. Moreover, they can cause multiple wounds and injuries as highlighted by the high proportion of polytraumatized and multiply traumatized casualties wounded by shell fragments.

In the kinetic energy equation $\mathrm{KE}=1 / 2 \mathrm{MV}$, the factor of mass is often overlooked. A tenfold increase in the mass of projectile increases kinetic energy almost eight times more than a rise in velocity of $100 \mathrm{~m} / \mathrm{sec}(1,3,16,18)$. If the kinetic energy release at impact of a low-velocity missile of higher mass is compared with that of a high velocity, and low mass projectile, Barach et al (3) has suggested larger tissue damage occurs in the former case because of greater energy release to the target. Blunt nonaerodynamic projectiles increase the temporary cavity volume with increasing velocity. No consideration has been given previously to thermal effects of hot shrapnel entering the body and the production of delayed necrosis, especially of tubular organs (vessels, intestine, ureter). This may be reflected in the complication rates in our data which suggest a higher morbidity risk for shell fragments than for bullet wounding, whereas the mortality risk is unaffected.

There are no medical ballistic data of kinetic energy of a shell fragment. The fragment velocity after a grenade explosion varies from 1,000 to $1,500 \mathrm{~m} / \mathrm{s}$, depending on type of gunpowder filling. About $70 \%$ of fragments weigh 5 to $100 \mathrm{~g}$ and produce kinetic energy amount of 2550 to $100,000 \mathrm{~J}$ each $(17,18)$. Considering drag forces, ballistic coefficient, retardation and striking velocity for both bullet and fragment, energy at impact of a shell fragment may sometimes be more than twenty times bigger than the energy of a bullet (3).

Our data revealed no significant difference in damage caused by an anticipated deeper penetration of muzzle high-velocity small-mass projectiles compared to shell fragments that are not expected to penetrate deeply $(1,3,5,7,8)$. In fact, the depth of penetration, ricochet effects and severity of damage, as judged by our multitrauma and polytrauma rates were higher in cases of shell fragment injuries.

Wounding of body regions in our series corresponded to that of previously published data $(16,17)$. Wounds to the extremities were more numerous than those to other body regions. It is of interest that although shell fragments caused significantly more head and neck wounds than bullets, the latter produced high mortality due to the high rate of cerebral damage. Forty percent of eases with bullet injuries to the brain died.

Our experience clearly suggests that individual shell fragment wounds are potentially equally detrimental as those of muzzle high-velocity bullets.

The high frequency of wounding by artillery shelling as experienced in Croatia 1991/92, has drawn attention to the mechanisms and consequences of their effects. It is suggested, that surgeons should not allow their operative decisions to be distracted unduly by the history of causation of injury, kinetic energy loss and possible shallow penetration (19). Patients with dangerous highly contaminated wounds should have their operative treatment planned keeping in mind possible thermal damage, missile tumbling and concomitant "smaller" injuries masked by the primary injury.

\section{Acknowledgement}

We thank Dr Matko Marušić for help and encouragement, and Dr Ana Marušić for the critical review of the article.

\section{REFERENCES}

1. FACKLER ML. Wound ballistics; A review of common misconceptions. JAMA 1988; 259 (18): 2730.

2. Fackler ML, Bellamy RF, Malinowski JA Wounding mechanism of projectiles striking at more than $1.5 \mathrm{~km} / \mathrm{see}$. J Trauma 1986; 26: 250 .

3. Barach E, Tomlanovich M, Nowak R. Ballistics: pathophysiologic examination of the woundine mechanisms of firearms I-II. J Trauma 1986; 26: 2250 374.

4. Amato JJ, Rich NM. Temporary cavity effects in bloo vessel injury by high velocity missiles J Cardiovasc Surg 1972; 13: 147.

5. Fackler ML, SurinchaK JS, Malinowski JA, et al. Bullet fragmentation: A major cause of tissue disruption. J Trauma 1984; 24: 35.

6. SwAN KG. Missile injuries: Wound ballistics and principles of management. Milit Med 1987; 152: 921.

7. BASIl A, MALEK M, OBeid M. Ballistic trauma to the abdomen: shell fragments versus bullets. J Trauma 1991; 31: 711.

8. Marcus NA, Blair WF, SHuck JM, Omer GE. Lowvelocity gunshot wounds to extremities. $J$ Trauma 1980; 20: 1061 .

9. SHEPARD GH. High-energy, low-velocity close-range shotgun wounds. J Trauma 1980; 20: 1065.

10. Glavina K, TuCak A, JanošI $\mathrm{K}$, et al. Deliberate military destruction of the General hospital in the city of Osijek. Croatian Med J 1992; 33 (War Suppl 1): 61.

11. Lackoví́ Z, Markeljeví́ J, Maruš́ć M. Croatian medicine in 1991 war against Croatia: a preliminary report. Croatian Med J 1992; 33 (War Suppl 2): 110.

12. LovRÍ́ Z. Reconstruction of major arteries of extremities after war injuries. $J$ Cardiovasc Surg (Turin) 1993; 34: 33. 
13. Lovrí Z, Wertheimer B, C̆Andrlí K, et al. War injuries of major extremity vessels. I Trauma 1994; 36: 248.

14. Marcikic, Kraus Z, DMitroví́ B, et al. War victims in Eastern Slavonia. Croatian Med J 1992; 33 (War Suppl 2): 75.

15. HARDWAY RM III. Vietnam wound analysis. J Trauma 1978: 18: 635.

16. COUPLAND RM. The role of reconstructive surgery in the management of war wounds. Ann R Coll Surg Engl 1991; 73: 21.
Z Lovrić, H Kuvez̆dic, D Prlić, B Wertheimer, K C̆andrlic $\stackrel{\square}{\square}$

17. RYAN JM, COOPER GJ, HaYwOOD IR, MILNER SM 茨 Field surgery on a future conventional battlefield:

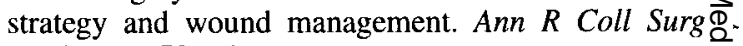
Engl 1991; 73: 13.

18. LOVRÍ́ Z, WERTHEIMER B, C̆ANDRLÍ́ K, et al. Are shell fragments as detrimental as high-velocity bullets? Croatian Med J 1994; 35: 253.

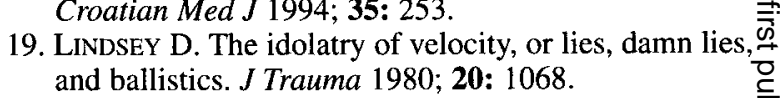

